Military Technical College Kobry El-Kobbah, Cairo, Egypt

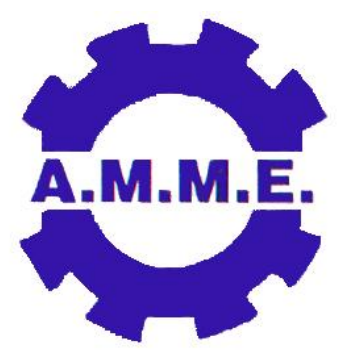

$14^{\text {th }}$ International Conference on Applied Mechanics and Mechanical Engineering.

\title{
Vibration control of tubular mono-poles using a novel concrete-steel composite design
}

By

\author{
Fady F. Barsoum
}

Amir Fam ${ }^{\dagger}$

\author{
Yi Zhang ${ }^{\ddagger}$
}

\begin{abstract}
:
Transmission line and light mono-poles are susceptible to structural vibration resulting from wind loads. Vibration mitigation and strengthening of steel poles have been studied. More recently a composite steel-concrete monopole was developed to support higher loads while having smaller ground line dimensions. The pole features a thin-walled hollow steel tube partially filled with concrete near the base to provide stability to the thin-walled tube. However, the dynamic properties of the newly developed poles were never investigated. Also, no attempts were made to investigate the optimal amount of concrete filling, to enhance the response of the poles when subjected to dynamic wind loads. In this paper, a finite element-based analysis was conducted to calculate the natural frequencies and mode shapes of conventional hollow steel poles. Results were verified using available numerical and experimental data. The method was then employed to calculate the natural frequencies and mode shapes of steel poles partly filled with concrete. A parametric study of the effect of the concrete filling length was also performed and utilized to find the optimal length of concrete filling. The new optimized composite pole features natural frequencies higher than the inherited frequencies of typical wind loads to better control wind-induced vibrations.
\end{abstract}

\section{Keywords:}

Poles, tubular structures, structural dynamics, GFRP, composite, steel, concrete, wind, natural frequency

\footnotetext{
* Associate Professor, Embry-Riddle Aeronautical University, Florida, USA

† Professor and Canada Research Chair, Queen's University, Ontario, Canada

¥Undergraduate Student, Embry-Riddle Aeronautical University, Florida, USA
} 


\section{Introduction:}

Tapered mono-poles are generally used for telecommunication, electric transmission, traffic signs or light support. Poles are traditionally constructed using wood, steel or concrete. Steel is commonly used in North America (Fam et al. [5]). Long mono-poles are vulnerable under severe weather conditions. For wind velocities as low as 17 to $46 \mathrm{mph}$, a sway of approximately 8 to 12 inches has been estimated for the top-of-pole movement due to vibrations (Manis et al. [8]). Wind-induced vibrations endanger the stability and performance of poles, and could even cause them to fail. Recently a number of failures of cantilevered structures have been reported, which are likely due to the fatigue caused by wind-induced vibrations (Phares et al. [11]). The frequency of wind loads tends to couple with the natural frequency of the structure when it approaches the latter one, and the displacements of the structure will be greatly amplified.

Phares et al. [11] indicated that frequencies present in natural wind are usually up to $2 \mathrm{~Hz}$. According to Caracoglia et al. [1], the first mode of a typical steel pole has a frequency that ranges from 1.7 to $1.8 \mathrm{~Hz}$. The pole is very likely to resonate when subject to wind loads that typically have frequencies lower than $2 \mathrm{~Hz}$. The field tests done by Cook et al. [2] on a number of traffic poles on the roads of Florida have indicated that the first natural frequencies of tested poles are from 0.7 to $1.2 \mathrm{~Hz}$. Therefore, in regions under frequent severe weather like Florida, when the wind speed couples with the natural frequency of a pole, resonance will occur and may lead to fatigue failure.

Fouad et al. [6] have developed a new "concrete-filled steel tube" (CFST) electric transmission line mono-pole structure to provide a more efficient load carrying capability for pole applications. The advantages of the CFST that were considered included: the ability to carry significantly higher loads, using longer spans, and reduction in pole dimensions at ground line. However, the dynamic characteristics of the new CFST were not considered. Fam et al. [5] and Son et al. [13] have also explored complete and partial concrete filling for glass fiber-reinforced polymer tubular poles. Poles were modeled and concrete filling was optimized. Results indicated that complete concrete filling along the full length is not necessary, and that it is more efficient in tubes with large D/t (diameter-to-thickness) ratios. Numerical and experimental studies of tubular steel poles with partial concrete filling subjected to static loads have been conducted [9] and showed that the optimal length of concrete filling under ultimate static loads is $46 \%$ of the total length for the tube used. Again the dynamic characteristics of the partially concreted filled steel and glass-fiber reinforced polymer tube poles have not been studied.

Maximum amplification in the response of a structure occurs when the dynamic load applied to a structure has frequencies that couple with the natural frequencies of the structure. This is when resonance occurs. Among these frequencies, the lowest natural frequency, which is the one associated with the first mode, is the most significant. The goal of this paper is to present the new composite design to better control the vibration of poles as they become subjected to wind loads. Rather than investing in fatigue analysis, this paper proposes a new optimized 
design to control vibration of poles under service conditions using a cost-effective approach that minimizes the probability of resonance by designing poles with a higher natural frequency than those of traditional poles. The new design has a lighter weight than the traditional concrete poles, and the construction and maintenance costs are reduced. This paper investigates the natural frequencies of tapered hollow steel poles and tapered concrete-filled steel tubes (CFSTs). Since the CFST poles have higher natural frequencies than the hollow ones, they are expected to have better control of the vibration response when subjected to wind loads. The results of these investigations and the effect of different parameters on the natural frequencies of the poles are studied and presented. An optimal design utilizing the required concrete filling length for the best dynamic performance is also presented.

\section{Research Significance}

Vibrations induced by high-speed wind may cause poles to fail. In February 2003, about 140 tapered light poles in western Illinois have collapsed in a storm (Phares et al. [11]). During hurricane Andrew which stroke south Florida in 1992, about 21,100 utility poles were downed (Deering et al. [3]), each of them costing $\$ 5,000$ to $\$ 30,000$. Pole failures due to windinduced vibrations happen frequently across the nation. Over $10 \%$ of the high-mast light poles in lowa have fatigue problems. The Wisconsin Department of Transportation has experienced failures of high luminary support structures across the state. The Missouri Department of Transportation discovered and documented several failures of cantilever poles in 1997 (Phares et al. [11]).

Wind-induced failure of traffic poles has not been sufficiently studied neither has it been used as a design criteria by the manufactures. A recent report by Manis et al. [8] stated that the standard one-year warranty of certain traffic pole manufacturer does not cover "naturally occurring harmonic vibration light pole failures." Enquires have been forwarded to various pole manufacturers, yet "none of them warrant failure of the poles due to harmonic vibration". There are millions of support poles across the nation. The price is normally $\$ 10,000$ to $\$ 20,000$ per pole. Thus, a new design of mono-poles that can stand wind loads is highly desirable.

\section{Methodology}

In order to control the dynamic excitation and displacement amplification, the new design seeks to increase the natural frequency of the first mode of the pole. Concrete filling is employed to increase the stiffness and thus the frequency as a low-cost alternative. It increases the stiffness of the structure effectively while the gain in mass is insignificant, since full length of concrete filling is not necessary (Fam et al. [5]). A certain length of concrete filling is enough to provide the best dynamic performance of the poles, and thus extra filling is not necessary.

Finite element analyses (FEAs) were performed using Pro/MECHANICA [12]. The FEAs were used to obtain the natural frequencies of the pole. The FEA model uses only shell elements. To verify the effectiveness of the use of shell elements and the Finite Element Method (FEM) used in this paper, a tapered steel pole from a previous research program was developed 
using Pro/ENGINEER and analyzed using Pro/MECHANICA. The results matched well the numerical and experimental results observed in the other studies. After the approach had been verified, a model of tapered steel pole with partial concrete filling was developed and analyzed. An optimization study was completed to find the optimal length of the concrete filling for a popular class 5 steel pole, for the best control of wind-induced vibrations. Finally, the effectiveness of concrete filling for increasing the natural frequency of the poles was presented and design recommendations were made.

In addition, three different lengths of $0.076 \mathrm{~m}$ ( 3 inch) outer diameter steel tubes with different concrete filling lengths were tested in the laboratory to investigate the effect of concrete filling on increasing the natural frequencies. The optimal percentage of concrete filling ranged from $37 \%$ to $43 \%$ for tube lengths of $2 \mathrm{~m}(6.55 \mathrm{ft})$ to $2.61 \mathrm{~m}(8.55 \mathrm{ft})$. At optimal filling, the first natural frequencies of the poles increased by $18 \%$ to $26 \%$. Concrete filling proved to be an effective way of increasing the natural frequency of cantilevered mono-poles. The numerical results are in agreement with the results from the experimental study with a difference of less than $10 \%$.

\section{Modeling}

Pro/MECHANICA uses P-elements for convergence analysis. This is different from most other FEA programs that use $\mathrm{H}$-elements for convergence. $\mathrm{H}$-element programs use low order interpolating polynomials for each element. In these programs, accuracy is related to the convergence analysis, which means that in order to get a more accurate result, the programs have to constantly refine and recreate finer meshes (Toogood [14]). $\mathrm{H}$ convergence requires longer run time and its results may be inaccurate in regions of interest.

In Pro/MECHANICA, instead of constantly refining and recreating finer meshes, convergence is achieved by using higher order interpolating polynomials for the elements that need it. The use of higher order polynomials for convergence analysis leads to the P-element class of FEA methods. In Pro/MECHANICA, the elements are fewer and the same mesh is used in all iterations of the analysis. The use of P-elements for convergence analysis enables the program to automatically generate a "good" mesh that may also be used to perform sensitivity and optimization studies without constantly re-meshing the model. This approach of Pro/MECHANICA makes the analysis easier and faster, and the results are more accurate than those of the H-elements programs under certain circumstances (Toogood [14]).

Pro/ENGINEER and Pro/MECHANICA are used to model and perform finite-element analyses of a prismatic steel pole. Both solid and shell element have been used to model the pole with 400 inch of length, 8 inch of diameter and 0.4 inch of thickness, to verify the validity of using shell elements. The use of shell elements is simpler in meshing, easier and faster to solve. The results obtained from both the solid and shell models, for the first five modes of natural frequencies are shown in Table 1. It can be seen that the results are very close, with a maximum difference less than $0.1 \%$. Therefore, shell elements are used to model the steel tubes throughout this paper. 
Table (1): Comparison of the first five modes of natural frequencies obtained from solid and shell element models $(\mathrm{Hz})$

\begin{tabular}{|c|c|c|c|c|c|c|}
\hline $\begin{array}{c}\text { Element } \\
\text { type }\end{array}$ & $\begin{array}{c}\text { No. of } \\
\text { elements }\end{array}$ & $\begin{array}{c}\text { Mode } \\
\mathbf{1}(\mathbf{H z})\end{array}$ & $\begin{array}{c}\text { Mode } \\
\mathbf{2}(\mathbf{H z})\end{array}$ & $\begin{array}{c}\text { Mode } \\
\mathbf{3}(\mathbf{H z})\end{array}$ & $\begin{array}{c}\text { Mode } \\
\mathbf{4}(\mathbf{H z})\end{array}$ & $\begin{array}{c}\text { Mode } \\
\mathbf{5}(\mathbf{H z})\end{array}$ \\
\hline Solid & 15656 & 1.872 & 11.69 & 32.55 & 63.27 & 77.43 \\
\hline Shell & 86 & 1.870 & 11.68 & 32.52 & 63.21 & 77.47 \\
\hline Difference & & $0.11 \%$ & $0.59 \%$ & $0.09 \%$ & $0.09 \%$ & $.05 \%$ \\
\hline
\end{tabular}

\subsection{Model and Finite-Element Analysis Verification}

To verify the validity of the model and finite-element analysis used in this paper, results are compared to those from the FE analysis and experiments performed by Caracoglia et al. [1] for a tapered steel pole, as shown in Fig. 1. The model is developed in Pro/ENGINEER with a length of 480.3 inch $(12.2 \mathrm{~m})$, top diameter of 4.02 inch $(102 \mathrm{~mm})$, bottom diameter of 9.49 inch $(241 \mathrm{~mm})$ and a constant wall thickness of 0.158 inch $(4 \mathrm{~mm})$. The material properties of the steel used are listed in Table 2. A shell mesh of 170 elements was utilized and is shown in Fig. 2. The FE model has 135 nodes, 305 edges and 170 faces. The results of analysis are presented in Table 3 and compared to those of Caracoglia et al. [1].

Table (2): Steel material properties

Density $(\rho)=0.282771 \mathrm{lb} / \mathrm{in}^{3}\left(7827.1 \mathrm{~kg} / \mathrm{m}^{3}\right)$
Young's Modulus $(\mathrm{E})=29000 \mathrm{ksi}(200 \mathrm{GPa})$
Poisson's Ratio $(\mathrm{U})=0.29$

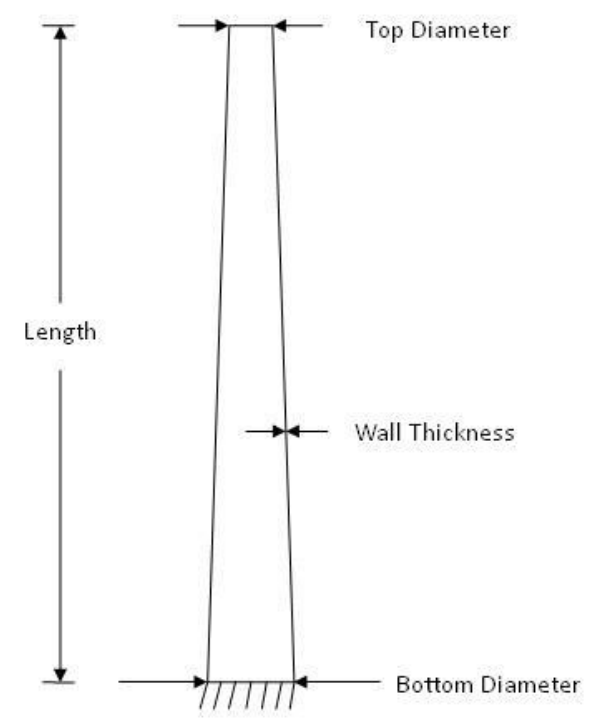

Figure (1): Tapered steel pole

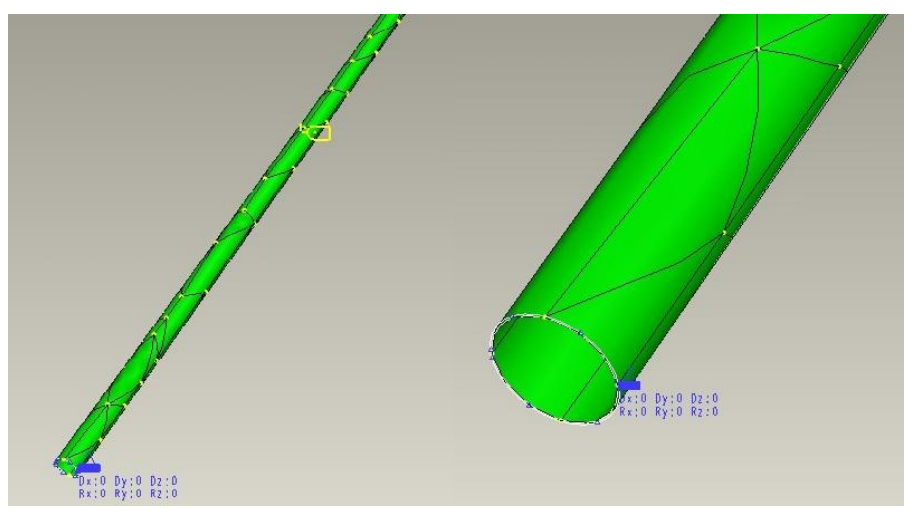

Figure (2): Shell element mesh for hollow tapered steel pole 
Table (3): Comparison of the results between current study and Caracoglia et al. [1]

\begin{tabular}{|c|c|c|c|}
\hline Mode & $\begin{array}{c}\text { FE f }(\mathrm{Hz}) \text { Barsoum et al. } \\
\text { (current study) }\end{array}$ & $\begin{array}{c}\text { FE } \mathrm{f}(\mathrm{Hz}) \\
\text { Caracoglia et al. }\end{array}$ & $\begin{array}{c}\text { Experiments }(\mathrm{Hz}) \\
\text { Caracoglia et al. }\end{array}$ \\
\hline 1 & 1.78 & 1.79 & 1.63 \\
\hline 2 & 7.96 & 8.01 & 7.20 \\
\hline 3 & 20.05 & 20.19 & - \\
\hline 4 & 37.95 & 38.21 & - \\
\hline 5 & 61.53 & 61.90 & - \\
\hline
\end{tabular}

The maximum difference between the FEA results from this research when compared to those from FEA of Caracoglia et al. [1] is less than $0.7 \%$, and less than $9.2 \%$ compared to the test results from Caracoglia et al. [1]. Therefore, the FE model and FEA presented here are justified.

\subsection{Composite Tapered Steel Pole with Partial Concrete Filling}

After the tapered steel pole model has been verified, a composite model of the popular class 5 tapered steel pole partly filled with concrete is developed. The dimensions of a class 5 pole are given in Table 4. The model is fixed at the bottom and free to vibrate at the top. The steel tube is modeled with 125 shell elements, and the concrete filling of 216 in. of length is modeled with 81 solid elements. A "compress the shell pair to the inner surface" command in Pro/MECHANICA is employed in idealizing the steel part to make sure that the outer surface of the concrete filling is in direct contact with the inner surface of the steel pole. The properties of the concrete filling used are shown in Table 5. The mesh of the composite model is shown in Fig. 3. It utilizes 206 hybrid elements with 97 nodes, 282 edges and 267 faces.

Table (4): Class 5 steel pole properties Length $=480$ inch $(12.2 \mathrm{~m})$ Bottom diameter $=11.8$ inch $(0.3 \mathrm{~m})$ Top diameter $=5.1$ inch $(0.13 \mathrm{~m})$ Thickness $=0.118$ inch $(3 \mathrm{~mm})$
Table (5): Concrete material properties Density $(\rho)=0.0867 \mathrm{lb} / \mathrm{in} 3(2400 \mathrm{~kg} / \mathrm{m} 3)$ Young's Modulus $(\mathrm{E})=4351 \mathrm{ksi}(30 \mathrm{GPa})$ Concrete Strength ( $\left.\mathrm{f}^{\prime} \mathrm{C}=5827 \mathrm{psi}\right)(40$ $\mathrm{MPa}$ )

Poisson's Ratio $(\mathrm{U})=0.2$

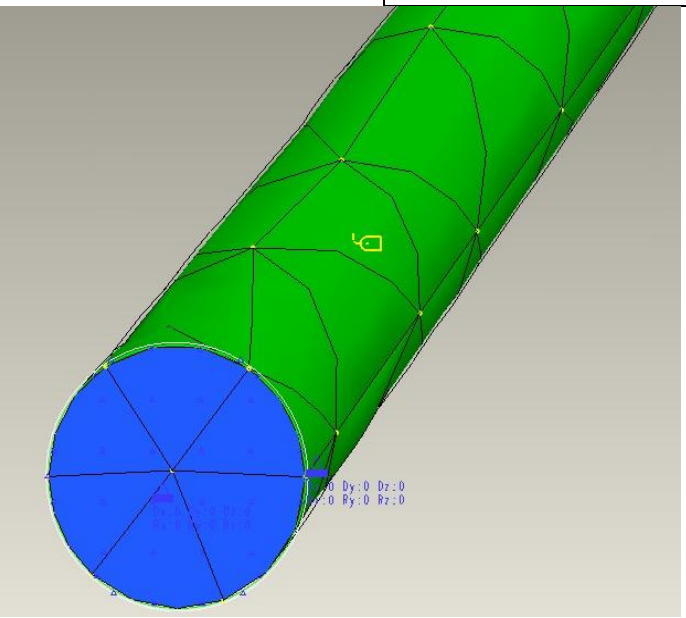

Figure (3): Solid and shell mesh for concrete filled pole 
The results presented in this paper are based on the assumption that the concrete will not crack. However, a quick check on the effect of the cracking of concrete has been performed. It showed that even when concrete cracking is considered, the flexural stiffness of the composite section is higher than that of the hollow steel pole, though less than that which does not take the effect of concrete cracking. Therefore, the results presented in this paper, based on the simplified model of concrete, are only presented to prove the concept. A more elaborate study will follow.

\section{Analysis of Tapered Steel Pole with Partical Concrete Filling}

The FE model for a class 5 tapered steel pole with partial concrete filling, as described in the modeling section 4.4 , is utilized to conduct a number of studies to find the optimal length of the concrete filling. The optimization goal is to maximize the first natural frequency of the pole. The effect of different percentage $(0 \%, 25 \%, 30 \%, 40 \%, 45 \% .50 \%, 55 \%, 65 \%, 75 \%$, and $100 \%$ ) of concrete filling along the pole length is studied for a class 5 pole. The results are shown in Fig. 4. From the results, it can be observed that the optimal length of filling is around $45 \%$. With $45 \%$ filling, the first natural frequency of class 5 pole reaches $3 \mathrm{~Hz}$. The increase in the first natural frequency is $36.4 \%$ when compared to that of the hollow pole without concrete filling $(2.2 \mathrm{~Hz})$. This proves that partial concrete filling increases the natural frequency of the pole and thus enhances its dynamic performance when subjected to typical or severe wind loads.

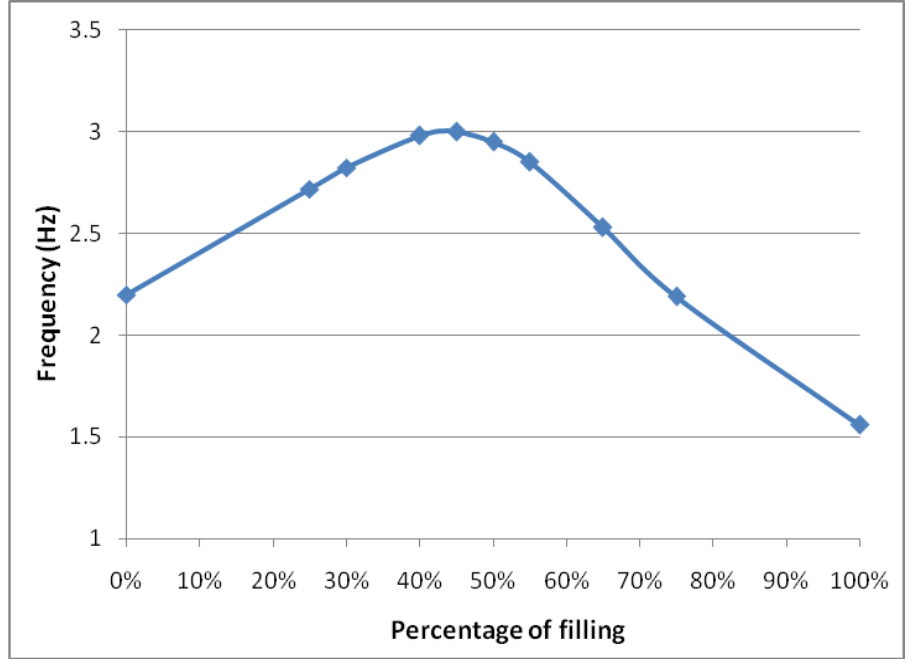

Figure (4): First mode vs. percentage of concrete filling for class 5 pole

A number of more focused studies are then completed for $42 \%$ to $47 \%$ concrete filling, and $43 \%$ to $44 \%$ is found to be the optimal length of filling. The first three mode shapes for the composite pole are presented in Figure 5. Mitchell has shown in his research that the optimal length of concrete filling for tubular steel poles under static loads is $46 \%$ [9]. Therefore, a concrete filling of $40 \%$ to $50 \%$ is recommended for the optimal static and dynamic performance. 

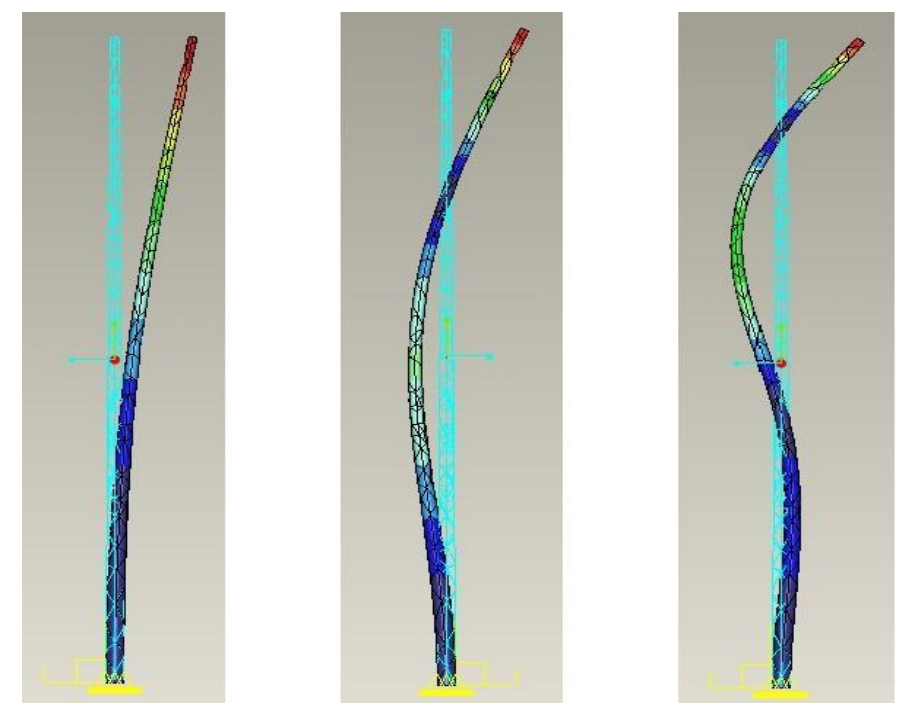

Figure (5): First 3 mode shapes for CFST with optimal concrete filling:

Mode 1: 3.0 Hz, Mode 2: $7.95 \mathrm{~Hz}$, Mode 3: $21.2 \mathrm{~Hz}$

Parametric studies for the effect of changing pole length and $D / t$ ratio on the first natural frequency under optimal concrete filling are performed. The results are shown in Fig. 6 and Fig. 7 and compared to those of hollow poles without concrete filling. The results show that the length and the bottom diameter are significant design parameters for concrete filled poles. However, more importantly is the significant increase of the first harmonic frequency due to the optimal partial concrete filling, which will reduce the wind-induced vibrations of the CFST poles when compared to that of hollow steel poles.

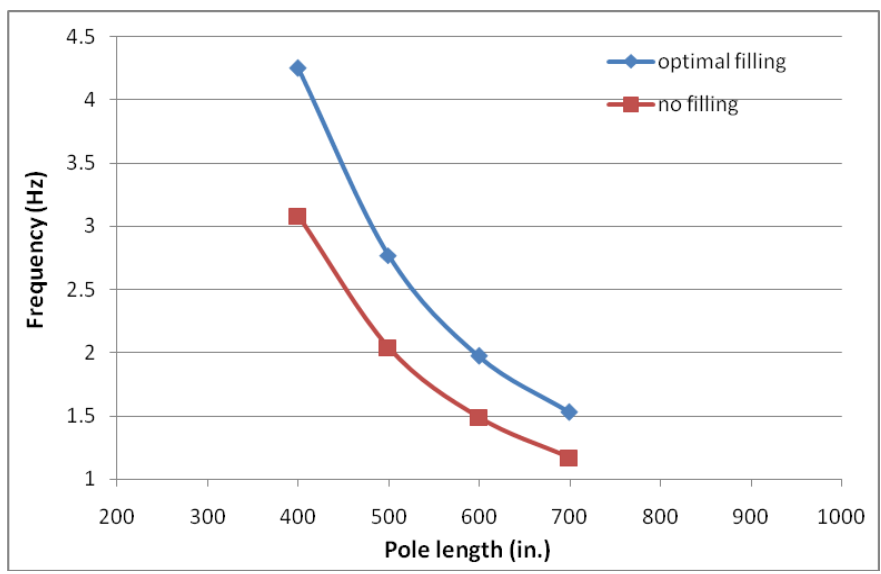

Figure (6): Effect of changing pole length at $D / t=100$ under optimal concrete filling, compared to the corresponding hollow steel pole 


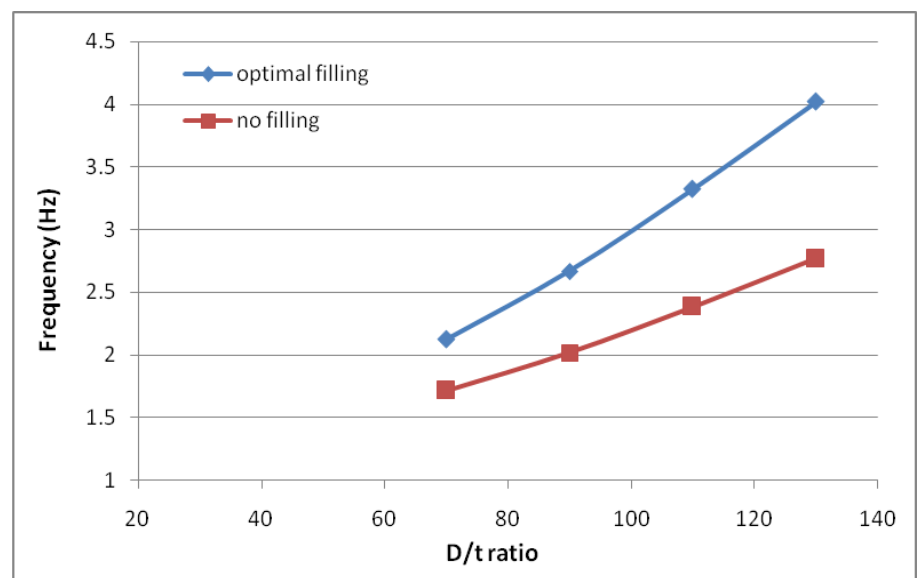

Figure (7): Effect of changing D/t ratio at pole length $=480$ in., under optimal concrete filling, compared to the corresponding hollow steel pole

For high performance concrete of f'c $=23307$ psi and Young's Modulus of $8702.26 \mathrm{ksi}$ (60 $\mathrm{GPa}$ [10], the effect on the natural frequency is even more notable. Parametric study on the effect of changing percentage of high performance concrete filling is conducted on the popular class 5 tapered steel pole, and compared to that of ordinary concrete filling. The results are shown in Fig. 8. At optimal filling which is $50 \%$ of the total length, the increase of the first natural frequency is as high as $62 \%$ (the increase is $36.4 \%$ for ordinary concrete of $f^{\prime} \mathrm{c}=5827 \mathrm{psi}$ on the same model).

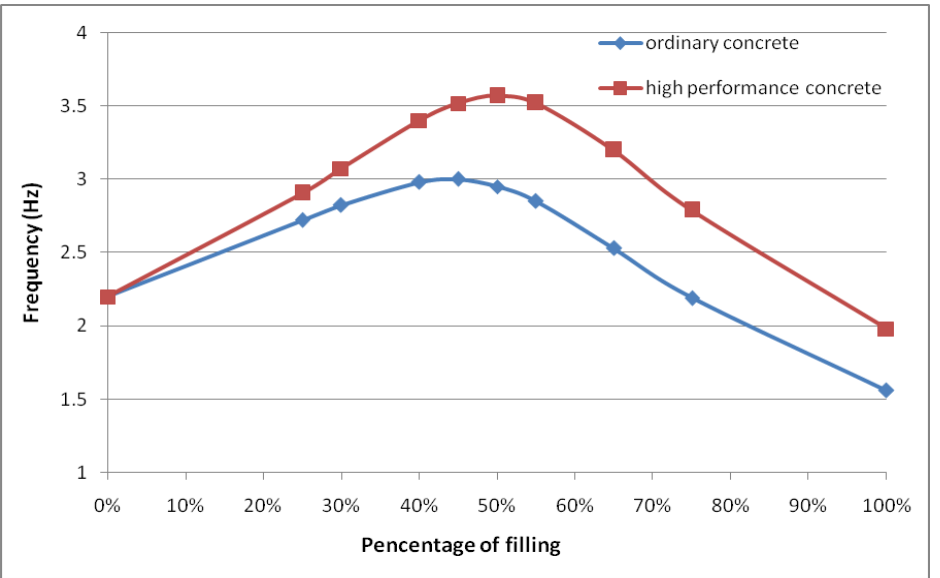

Figure (8): Comparison between the effect of partial concrete filling on the first natural frequency for class 5 pole using high performance concrete and ordinary concrete

\section{Conclusions:}

This article utilizes a finite element analysis to investigate the natural frequencies of tapered steel mono-poles with and without concrete filling. Hollow tapered steel poles are modeled using shell elements. The results from a modal analysis of the model agree with both numerical and experimental data from earlier studies. The following conclusions are drawn:

1. The use of partial concrete filling in hollow tubular poles is quite effective in increasing their first natural frequency by up to $45 \%$. The optimal length of filling was generally found to be about $45 \%$ of the length of the poles.

2. Decreasing the pole length or increasing base diameter increases the natural frequency of 
a CFST. However, the top diameter and wall thickness have insignificant effect on its natural frequency.

3. The proposed method, including linear elastic analysis of hollow tubular poles resulted in good agreement with experimental and analytical results of hollow tubular poles from literature.

\section{References:}

[1] Caracoglia L, Velazquez A. Experimental comparison of the dynamic performance for steel, aluminum and glass-fiber-reinforced-polymer light poles. Engineering Structures 2008; 30: 1113-1123.

[2] Cook RA, Bloomquist D, Kalajian MA, Cannon VA, Arnold D. Mechanical damping systems for traffic signal mast arms. A report to Florida Department of Transportation (FDOT). University of Florida, Department of Civil Engineering, 1998.

[3] Deering A, Thornton JP. Applications of solar technology for catastrophe response, claims management, and loss prevention. OSTI ID: 3772. National Renewable Energy Laboratory, Golden, CO (US), 1999.

[4] Elmarakbi A, Sennah K, Siriya P, Emam A. Parametric effects on the performance on the traffic light poles in vehicle crashes. International Journal of Crashworthiness 2006; 11(3): 217-230.

[5] Fam A, Son J. Finite element modeling of hollow and concrete-filled fiber composite tubes in flexure: Optimization of partial filling and a design method for poles. Engineering Structures 2008; 30: 2667-2676.

[6] Fouad FH, Steele JT. A hybrid monopole structure for electrical transmission lines. ASCE Conf. Proc. 253; 30 (2002); DOI: 10.1061/40642(253)30

[7] Le T, Abolmaali A, Motahari SA, Yeih W, Fernandez R. Finite element-based analyses of natural frequencies of long tapered hollow steel poles. Journal of Constructional Steel Research 2008; 64: 275-284

[8] Manis P, Jones W. Wind induced vibrations on light standards. Structure Magazine 2008; 3: 14-15.

[9] Mitchell JR. Experimental and numerical investigations into optimal concrete partial filling of FRP and steel tubular poles. Queen's University, 2008.

[10] Persson Bertil. Hydration and strength of high performance concrete. Advanced Cement Based Materials 1996; Volume 3; Issues 3-4: 107-123.

[11] Phares BM, Sarkar PP, Wipf TJ, Chang B. Development of fatigue design procedures for slender, tapered support structures for highway signs, luminaries, and traffic signals subjected to wind-induced excitation from vortex shedding and buffeting. lowa State University, 2007.

[12] Pro/ENGINEER Wildfire 3.0. Parametric Technology Corporation (PTC), 2007.

[13] Son J, Fam A. Finite element modeling of hollow and concrete-filled fiber composite tubes in flexure: Model development, verification and investigation of tube parameters. Engineering Structures 2008; 30: 2656-2666.

[14] Toogood R. Pro/ ENGINEER Wildfire 3.0: MECHANICA tutorial (structure/thermal). Schroff Development Corporation; 2006. 